\title{
Rendimiento de cosecha de diecisiete cultivares de papa (Solanum tuberosum L.) del grupo Phureja
}

\author{
Harvest performance of seventeen potato cultivar (Solanum \\ tubersosum L.) from the Phureja group
}

\section{Juan F. Seminario Cunya*; Alejandro Seminario Cunya; Antenor Domínguez Palacios; Berardo Escalante Zumaeta}

Programa de Raíces y Tubérculos Andinos, Facultad de Ciencias Agrarias, Universidad Nacional de Cajamarca. Av. Atahualpa $N^{\circ}$ 1050, Cajamarca, Peru.

Received February 1, 2016. Accepted May 19, 2017.

\begin{abstract}
Resumen
El objetivo de la investigación fue evaluar el rendimiento de tubérculos y las variables relacionadas de 17 cultivares de papa del grupo Phureja, de la región Cajamarca-Perú. El experimento se realizó en el valle de Cajamarca (2650 msnm) en diseño de bloques completamente randomizados, con 17 tratamientos (cultivares) y tres repeticiones, sembrados a 0,90 m entre surcos y 0,40 m entre plantas. Se evaluó altura de planta, número de tallos, número y peso total de tubérculos, número y peso de tubérculos comerciales, materia seca de tubérculos y follaje (\%), índice de cosecha, gravedad específica y rendimiento de tubérculos por hectárea. Los datos fueron tratados mediante análisis de varianza y prueba de rango múltiple de Tukey $(p \leq 0,05)$. El rendimiento de tubérculos varió de $8,2 \mathrm{t} \cdot \mathrm{ha}^{-1}$ a $27,4 \mathrm{t} \cdot \mathrm{ha}^{-1}$ y el promedio fue de $15,5 \mathrm{t} \cdot \mathrm{ha}^{-1}$. El índice de cosecha promedio fue de $65 \%$. Los tubérculos comerciales representaron entre $49 \%$ y $97 \%$. Los cultivares presentaron diferencias estadísticas altamente significativas en rendimiento por hectárea, altura de planta, número de tallos, número total de tubérculos, número de tubérculos comerciales y peso de tubérculos comerciales. Nueve cultivares fueron estadísticamente similares y superiores al resto, en rendimiento de tubérculos por hectárea. Un cultivar fue superior a todos los demás, en rendimiento de tubérculos comerciales.
\end{abstract}

Palabras clave: Papa criolla; grupo Phureja; rendimiento; índice de cosecha.

\begin{abstract}
The objective of the research was to evaluate the yield of tubers and related variables of 17 potato cultivars of the Phureja group from the Cajamarca-Peru region. The experiment was carried out in the Cajamarca Valley (2650 masl) in a randomized complete block design, with 17 treatments (cultivars) and three replications, planted at $0.90 \mathrm{~m}$ between rows and $0.40 \mathrm{~m}$ between plants. Plant height, number of stems, number and total weight of tubers, number and weight of commercial tubers, dry matter of tubers and foliage (\%), crop index, specific gravity and yield of tubers per hectare were evaluated. Data were analyzed using analysis of variance and Tukey's multiple rank test $(\mathrm{p} \leq 0.05)$. The yield of tubers varied from $8.2 \mathrm{t} \cdot \mathrm{ha}^{-1}$ to $27.4 \mathrm{t} \cdot \mathrm{ha}^{-1}$ and the average was $15.5 \mathrm{t}^{\cdot h a^{-1}}$. The average harvest rate was $65 \%$. Commercial tubers were between $49 \%$ and $97 \%$. The cultivars showed highly significant statistical differences in yield per hectare, plant height, number of stems, total number of tubers, number of commercial tubers and weight of commercial tubers. Nine cultivars were statistically similar and superior to the rest, in yield of tubers per hectare. One cultivar was superior to all others, in yield of commercial tubers.
\end{abstract}

Keywords: Creole potato; Phureja group; yield; harvest index.

\section{Introducción}

Los cultivares de papa del grupo Phureja, cuyas características pincipales son la falta de dormancia y su precocidad (Huamán y Spooner 2002, Huamán, 2008), estarían en riesgo en el Perú. Zimmerer (1991) señala

\footnotetext{
* Corresponding author

E-mail: jfseminario@yahoo.es (J. Seminario).
} 
que estas papas precoces casi han desaparecido en Paucartambo. En 1992, el mismo autor, reitera sobre la pérdida de estos cultivares en el sur del Perú. De Hann y Thiele (2005) indican que estos cultivares se siembran cada vez menos en Yauyos. Asimismo, de Hann (2009) indica que, en Huancavelica, los agricultores mantienen todos los cultivares reportadas previamente por C. Ochoa, excepto los Phureja. Por otro lado, Seminario y Zarpan (2011), estiman que, en Cajamarca, en 20 años, se perdió $21 \%$ de cultivares del grupo. Además, encontraron que el grupo, no está representado en las colecciones ex situ y los catálogos regionales registran dos cultivares en el mejor de los casos.

El grupo Phureja presenta un conjunto de ventajas, entre las cuales se mencionan: Buena aceptación y presencia en el mercado durante todo el año (Ligarreto y Suarez, 2003; Seminario y Zarpán, 2011). Buenas características culinarias y aptitud industrial (Rozo y Ramírez, 2011; Rivera et al., 2011; Zárate-Polanco et al., 2014; Martínez et al., 2015; Cruz et al., 2016). Niveles más altos de materia seca $(19 \%$ a $27,5 \%)$ que el grupo Tuberosum (18\% a 21\%) (Ligarreto y Suarez, 2003; Dobson et al., 2004; Burgos et al., 2007). Altos niveles de $\mathrm{Fe}$ y $\mathrm{Zn}$ (Dobson et al., 2004; Burgos et al., 2007). Rangos de proteína más elevados $(6,4 \%$ a $10,4 \%$ BS $)$ que el grupo Tuberosum - 6,8\% BS - (Peña, 2015). Altos niveles de vitamina $C$, carotenoides, fenoles totales y antioxidantes en general (Burgos et al., 2009; Bonierbale et al., 2009; Leyton-Forero et al., 2013; Molina et al., 2015; ParraGalindo, 2016). Más contenido de ácidos grasos $(885 \mu \mathrm{g} / \mathrm{g})$ que otros grupos de papa $(648 \mu \mathrm{g} / \mathrm{g})$ y dentro de éstos, niveles más altos de ácido $\alpha$-linolénico $(18: 3, n-3)$ y ácido linoleico (18:2, n-6), que en $S$. tuberosum. Esta composición en ácidos grasos explicaría el sabor característico de estas papas (Dobson et al., 2004). También, el grupo involucra materiales tolerantes a Phytophthora infestans (Escallón et al., 2005; Gabriel et al., 2013), al virus del amarillamiento de venas
(Guzmán y Rodríguez, 2010), a marchitez bacteriana - Ralstonia solanacearum (Moslemkhani et al., 2012; Patil et al., 2012), a sarna polvosa - Spongospora subterránea -- (Ramírez et al., 2013) y a la polilla guatemalteca - Tecia solanivora Povolny - (Cadena et al., 2005). Además, los estudios indican que los cultivares del grupo Phureja, son poco exigentes en nutrientes, sobre todo en $\mathrm{P}$ y $\mathrm{K}$, y por su corto periodo de crecimiento, no responden al fraccionamiento del fertilizante nitrogenado como las papas mejoradas. Estas últimas características se traducen en menores costos de producción (BecerraSanabria, 2007; Pérez et al., 2008; Rozo y Nustez, 2011; Bautista et al., 2012). Por las ventajas señaladas, estos cultivares constituyen fuente importante de genes para el mejoramiento genético (Rodríguez et al., 2013; Gabriel et al., 2013) y un buen prospecto como componente de la agricultura urbana (Vega, 2015). Sus moderados rendimientos $\left(9,5 \mathrm{t} \cdot \mathrm{ha}^{-1}\right)$ en parcelas comerciales (Rozo y Ramírez, 2011), son compensados por la calidad del producto, el menor costo de producción y los precios de mercado más altos, en relación a las papas mejoradas (Ligarreto y Suarez, 2003; Seminario y Zarpán, 2011). A pesar de su reconocida importancia biológica, económica y social, en el Perú, este grupo de papa no ha sido minuciosamente estudiado, sobre todo en su potencial de rendimiento. Por este motivo, en la presente investigación se estudió la capacidad para producir cosecha de 17 cultivares, seleccionados de una colección de trabajo de 48 cultivares, que mantiene el Programa de Raíces y Tubérculos Andinos de la Universidad Nacional de Cajamarca.

\section{Materiales y métodos}

El experimento se realizó en una parcela del Programa de Raíces y Tubérculos Andinos de la Universidad Nacional de Cajamarca, ubicada en el valle de Cajamarca a $2650 \mathrm{msnm}$. El periodo del cultivo correspondió a la mejor temporada del año, por presencia de lluvias, humedad relativa y temperatura más altas (Tabla 1 ). 
Tabla 1

Datos meteorológicos registrados en el valle de Cajamarca (Perú) (Periodo dic. 2013 - abril 2014)

\begin{tabular}{lccccc}
\hline \multirow{2}{*}{ Variable } & 2013 & \multicolumn{3}{c}{2014} & \multirow{2}{*}{ Promedio } \\
\cline { 2 - 5 } & dic & ene & feb & mar & \\
\hline Precipitación $(\mathrm{mm})$ & 52,8 & 62,0 & 100,0 & 215,9 & 107,7 \\
Humedad relativa $(\%)$ & 62,0 & 67,0 & 68,0 & 71,0 & 67,0 \\
Temperatura promedio $\left({ }^{\circ} \mathrm{C}\right)$ & 15,5 & 16,1 & 15,7 & 16,0 & 15,8 \\
Brillo solar (horas) & 6,3 & 6,2 & 5,0 & 3,1 & 5,2 \\
\hline
\end{tabular}

Fuente: Estación Meteorológica Augusto Weberbauer, Convenio UNC-SENAMHI (2014).

El suelo en donde se realizó el experimento fue de $\mathrm{pH}$ neutro y contenidos medios de calcáreo total, MO, N, P; alto en $\mathrm{K}$ y libre de sales (Tabla 2).

Se utilizaron 17 cultivares (Tabla 3) seleccionados, según la evaluación preliminar, como los más productivos, de una colección de 48 cultivares. De estos cultivares, ocho fueron probados en un experimento previo (Rojas y Seminario, 2014).

Se usó el diseño de bloques completamente randomizados (BCR), con 17 tratamientos (cultivares) y tres repeticiones. Cada unidad experimental estuvo conformada por una parcela de tres surcos de 10 plantas cada uno, de los cuales, se cosecharon ocho plantas del surco central, descartando las plantas de los extremos, para evitar el efecto de borde. Los distanciamientos fueron de $0,90 \mathrm{~m}$ entre surcos y $0,40 \mathrm{~m}$ entre plantas (27 778 plantas $\left.\cdot \mathrm{ha}^{-1}\right)$. Se usaron tubérculos semilla con peso promedio de de $45 \mathrm{~g}$, en estado de brotamiento múltiple.

Se fertilizó con 100-100-40 unidades de N, $\mathrm{P}, \mathrm{K}$, respectivamente, $\mathrm{y}$, como fuentes se usaron urea $(46 \% \mathrm{~N})$, superfostafo simple de calcio $\left(21 \% \mathrm{P}_{2} \mathrm{O}_{5}\right)$ y cloruro de potasio $\left(60 \% \mathrm{~K}_{2} \mathrm{O}\right)$. La mezcla de fertilizantes se aplicó a la siembra. Además, se aplicó, a la siembra, humus de lombriz, en la proporción de $5 \mathrm{t} \mathrm{ha}^{-1}$. Los deshierbos, el aporque y el control sanitario, se realizaron de acuerdo a los procedimientos recomendados para parcelas comerciales. El cultivo se mantuvo exclusivamente con las lluvias de la temporada.

Las variables evaluadas, por planta, fueron altura de planta (AP), número de tallos (NT), número total de tubérculos (NTT), número de tubérculos comerciales (NTC), peso total de tubérculos (PTT) y peso de tubérculos comerciales (PTC). El PTC incluyó aquellos tubérculos de $\geq 2 \mathrm{~cm}$ de diámetro, según la clasificación de Rodríguez et al. (2009). El rendimiento por hectárea se obtuvo mediante la ecuación de Hay y Walker $(1989,190)$ que considera tres componentes básicos del rendimiento. Es decir, en nuestro caso: Rendimiento $\left(\mathrm{kg} \cdot \mathrm{ha}^{-1}\right)=27778$ plantas $\mathrm{x} \mathrm{N}^{\circ}$ tubérculos por planta $\mathrm{x}$ peso promedio del tubérculo fresco $(\mathrm{kg})$. Finalmente, el rendimiento se expresó en toneladas por hectárea $\left(\mathrm{t} \cdot \mathrm{ha}^{-1}\right)$.

Además, para cada cultivar y mediante una muestra de dos plantas por bloque, se evaluó la materia seca de tubérculo y del follaje (\%). Se tomó una submuestra de cinco tubérculos de tamaño mediano, se lavaron y cortaron en cubos de 1 a $2 \mathrm{~cm}$, se mezclaron y se tomaron $200 \mathrm{~g}$ (peso fresco), en dos repeticiones. Se colocaron en papel aluminio y luego en estufa a 75 ${ }^{\circ} \mathrm{C}$ por 72 horas (CIP 2010). El follaje de las plantas muestra se cortó en trozos de menos de 2 a $3 \mathrm{~cm}$ de largo, se mezclaron, se tomaron $200 \mathrm{~g}$, en dos repeticiones, y se colocaron en estufa a $75{ }^{\circ} \mathrm{C}$ por 72 horas. El porcentaje de materia seca, en ambos casos, se determinó con la fórmula: (peso seco / peso fresco) $\bullet 100$. Los valores de la materia seca del tubérculo y del follaje fueron usados para calcular el índice de cosecha (IC), conforme a lo establecido por Gardner et al. (1985). La gravedad específica (GE) del tubérculo se evaluó en una muestra de $1 \mathrm{~kg}$ por cultivar, siguiendo el procedimiento de Díaz et al. (2008). Los datos fueron tratados mediante análisis de varianza (ANOVA) y prueba de rango múltiple de Tukey $(\mathrm{p} \leq 0,05)$. 
Tabla 2

Análisis del suelo en donde se realizó el experimento

\begin{tabular}{lcc}
\hline Característica & Unidad & Valor \\
\hline $\mathrm{pH}$ & & 7,3 \\
Calcáreo total & $(\%)$ & 1,9 \\
$\mathrm{CE}$ & $(\mu \mathrm{mohs} / \mathrm{cm})$ & 859,5 \\
$\mathrm{MO}$ & $(\%)$ & 3,8 \\
$\mathrm{~N}$ total & $(\%)$ & 0,15 \\
$\mathrm{P}$ disponible & $(\mathrm{ppm})$ & 13,8 \\
K disponible & $(\mathrm{ppm})$ & 213,3 \\
\hline
\end{tabular}

pH: potencial de hidrogeniones, CE: conductividad eléctrica, MO: materia orgánica, $\mathrm{N}$ : nitrógeno, $\mathrm{P}$ : fósforo, K: potasio.

Fuente: Laboratorio Tecnología y Desarrollo Agrícola J.D.S.R.L. Registro N JD15-0122-2013.

\section{Resultados y discusión}

\subsection{Rendimiento de tubérculos por hectárea}

Se encontraron diferencias estadísticas altamente significativas entre cultivares para el rendimiento de tubérculos expresado en toneladas por hectárea (Tabla 4), es decir, los cultivares se comportaron de modo diferente respecto a esta variable. La prueba de rango múltiple de Tukey (Figura 1) indicó que nueve cultivares (Roja 2, Amarilla mahuay, Piña amarilla, Amarilla, Montañera 3, Porpora, Limeña huachuma, Bola de potro y Pierna de viuda 2) tuvieron un rendimiento superior al resto de cultivares. Estos rendimientos variaron de
13,6 tha $\mathrm{h}^{-1}$ a $27,4 \mathrm{t} \cdot \mathrm{ha}^{-1}$. Un segundo grupo, lo conformaron los cultivares Montañera 2, Shoga amarilla, Clavelina 2, Montañera 1 y Blanca, con rendimientos intermedios comprendidos entre 11,5 y $11,8 \mathrm{t} \cdot \mathrm{ha}^{-1}$. Los cultivares Mulla, Peruanita 3 y Huagalina, constituyeron el tercer grupo con rendimientos $\left(6,3\right.$ a $\left.8,9 \mathrm{t} \cdot \mathrm{ha}^{-1}\right)$ estadísticamente inferiores al resto de cultivares. Esta amplia capacidad productiva de los cultivares en estudio, permite la selección de los mejores para estudios específicos.

Diversas investigaciones señalan una marcada variación en el rendimiento de los cultivares del grupo Phureja. Por ejemplo, Escallón et al. (2005) encontró que el rendimiento de 25 genotipos redondos varió desde 2,6 th ha ${ }^{-1}$ hasta 21,6 t $\cdot \mathrm{ha}^{-1}$; y, Santos (2005), en una prueba de cuatro cultivares, registró rendimientos de 30,4 a 49,6 $\mathrm{t} \mathrm{ha}^{-1}$, que serían los rendimientos experimentales más altos para el grupo. En Cajamarca, Seminario y Medina (2009), trabajaron once cultivares y encontraron rendimientos de 12 a $18 \mathrm{t} \cdot \mathrm{ha}^{-1}\left(14 \mathrm{t} \cdot \mathrm{ha}^{-1}\right.$, en promedio). Asimismo, Rojas y Seminario (2014) trabajaron con diez cultivares $y$ registraron rendimientos de 5 a $11,5 \mathrm{t} \cdot \mathrm{ha}^{-1}$ (8,6 $\mathrm{t} \cdot \mathrm{ha}^{-1}$, en promedio). La información que aporta esta investigación sobre rendimiento de cosecha es importante, por cuanto, en Perú, existen escasos estudios sobre la capacidad productiva del grupo Phureja.

\section{Tabla 3}

Nombres y códigos de 17 cultivares de papa grupo Phureja en estudio

\begin{tabular}{lllllll}
\hline$N^{\circ}$ & Cultivar & Código & & $N^{\circ}$ & Cultivar & Código \\
\cline { 1 - 3 } \cline { 5 - 6 } & Bola de potro & Bolp & & 10 & Montañera 2 & Mon2 \\
2 & Roja 2 & Roj2 & & 11 & Limeña huachuma & Limh \\
3 & Peruanita 3 & Per3 & & 12 & Pierna de viuda 2 & Piv2 \\
4 & Montañera 1 & Mon1 & & 13 & Porpora & Porp \\
5 & Shoga amarilla & Shoa & & 14 & Clavelina 2 & Clav2 \\
6 & Huagalina & Huag & & 15 & Amarilla & Amar \\
7 & Mulla & Mull & & 16 & Montañera 3 & Mon3 \\
8 & Amarilla mahuay & Amah & & 17 & Blanca & blanc \\
9 & Piña amarilla & Piña & & & \\
\hline
\end{tabular}

Los nombres con negrita corresponden a cultivares que se probaron en un experimento previo, en la misma localidad (Rojas y Seminario, 2014). 


\section{Tabla 4}

Cuadrados medios y significación del ANOVA para el rendimiento $\left(\mathrm{t} \mathrm{ha}^{-1}\right)$ y sus componentes de 17 cultivares de papa chaucha (S. tuberosum grupo Phureja)

\begin{tabular}{lllllllll}
\hline FV & GL & $\mathrm{t} \mathrm{ha}^{-1}$ & AP & NT & NTT & NTC & PTT & PTC \\
\hline Bloques & 2 & 95206,06 & $1098,61^{* *}$ & 0,02 & 0,65 & $0,76^{*}$ & 120728,49 & 92459,84 \\
Tratamiento & 16 & $99581,49^{* *}$ & $320,45^{* *}$ & $0,15^{* *}$ & $2,97^{* *}$ & $0,78^{* *}$ & $132259,96^{* *}$ & $95578,56^{* *}$ \\
Error & 32 & 23934,68 & 84,38 & 0,051 & 0,71 & 0,21 & 31672,45 & 30265,32 \\
CV $(\%)$ & & 31,8 & 12,10 & 13,47 & 18,55 & 15,80 & 32,10 & 37,93 \\
\hline
\end{tabular}

FV: Fuentes de variación, GL: Grados de libertad. *: Significativo, **: Altamente significativo. Los datos de NT, NTT y NTC fueron transformados mediante $Y=\sqrt{ } X$, antes del análisis.

\subsection{Variables relacionadas con el rendimiento de cosecha}

Altura de planta (AP). Las plantas fueron pequeñas midieron entre 56,5 y $94 \mathrm{~cm}$ y $75,9 \pm 20,3 \mathrm{~cm}$ en promedio (Tabla 5). Rojas y Seminario (2014) con materiales de la misma región (ocho de los cuales son los mismos que se usaron en el presente experimento), encontraron que la altura de planta varió entre 61 y $82 \mathrm{~cm}$ y $73 \pm 6,4$ cm. Hernández y Suarez (2009), en 59 accesiones de la colección del grupo Phureja que mantiene CORPOICA, encontraron plantas con altura promedio de 86,5 $\mathrm{cm}$ y el rango de 45 a $150 \mathrm{~cm}$. Existen diferencias altamente significativas entre tratamientos (Tabla 4) y la prueba de rango múltiple de Tukey (Tabla 6) indicó que los cultivares Montañera 1 y Clavelina 2, produjeron plantas con altura estadísticamente inferior al resto de cultivares.

Número de tallos (NT). Los tratamientos mostraron diferencias altamente significativas para esta variable (Tabla 4). Sin embargo, la prueba de Tukey (Tabla 6) indicó que todos los tratamientos son similares, con ventajas numéricas a favor de los cultivares Roja 2, Amarilla mahuay y Shoga amarilla.

El promedio fue de 3 tallos por planta y la variación de 1 a 4 tallos por planta (Tabla 5). En un ensayo anterior, Rojas y Seminario (2014), encontraron 5 tallos por planta, en promedio. Es explicable esta variación porque depende del cultivar, del estado fisiológico del tubérculo semilla al momento de la siembra y de la densidad de plantación.
Número total de tubérculos (NTT). Los tratamientos presentaron diferencias altamente significativas en esta variable (Tabla 4), sin embargo, la prueba de rango múltiple de Tukey (Tabla 6) indicó que los cultivares son estadísticamente similares, con ventaja numérica para Porpora y Pierna de viuda 2.

El promedio fue de $22 \pm 9$ tubérculos por planta y, varió de 9 a 35 tubérculos por planta, equivalentes a 25 y 97 tubérculos $\mathrm{m}^{-2}$, respectivamente (Tabla 5). Arias et al. (1996) en la variedad 'yema de huevo' de Colombia, encontraron entre 90 y 120 tubérculos $/ \mathrm{m}^{2}$, variando según la densidad de plantación. Rojas y Seminario (2014), en 10 cultivares, encontraron 47 tubércu$\mathrm{los} / \mathrm{m}^{2}$, en promedio, con rango de 28 a 67 tubérculos $/ \mathrm{m}^{2}$.

Número de tubérculos comerciales (NTC). Existen diferencias estadísticas altamente significativas entre tratamientos (Tabla 4); sin embargo, la prueba de Tukey (Tabla 6) mostró que las diferencias entre tratamientos son solamente numéricas. El NTC representó, en promedio, $42 \%$ del total de tubérculos producidos por planta, $\mathrm{y}$ varió de 30\% (Porpora), a 61\% (Bola de potro y Montañera). Esta respuesta, probablemente fue favorecida por la temperatura y la precipitación pluvial de la temporada (Tabla 1). En una estación productiva climáticamente distinta (Estiaje) y bajo riego, Rojas y Seminario (2014), encontraron que los tubérculos comerciales representaron $16 \%$, en promedio (rango de $13 \%$ y $20 \%)$. 


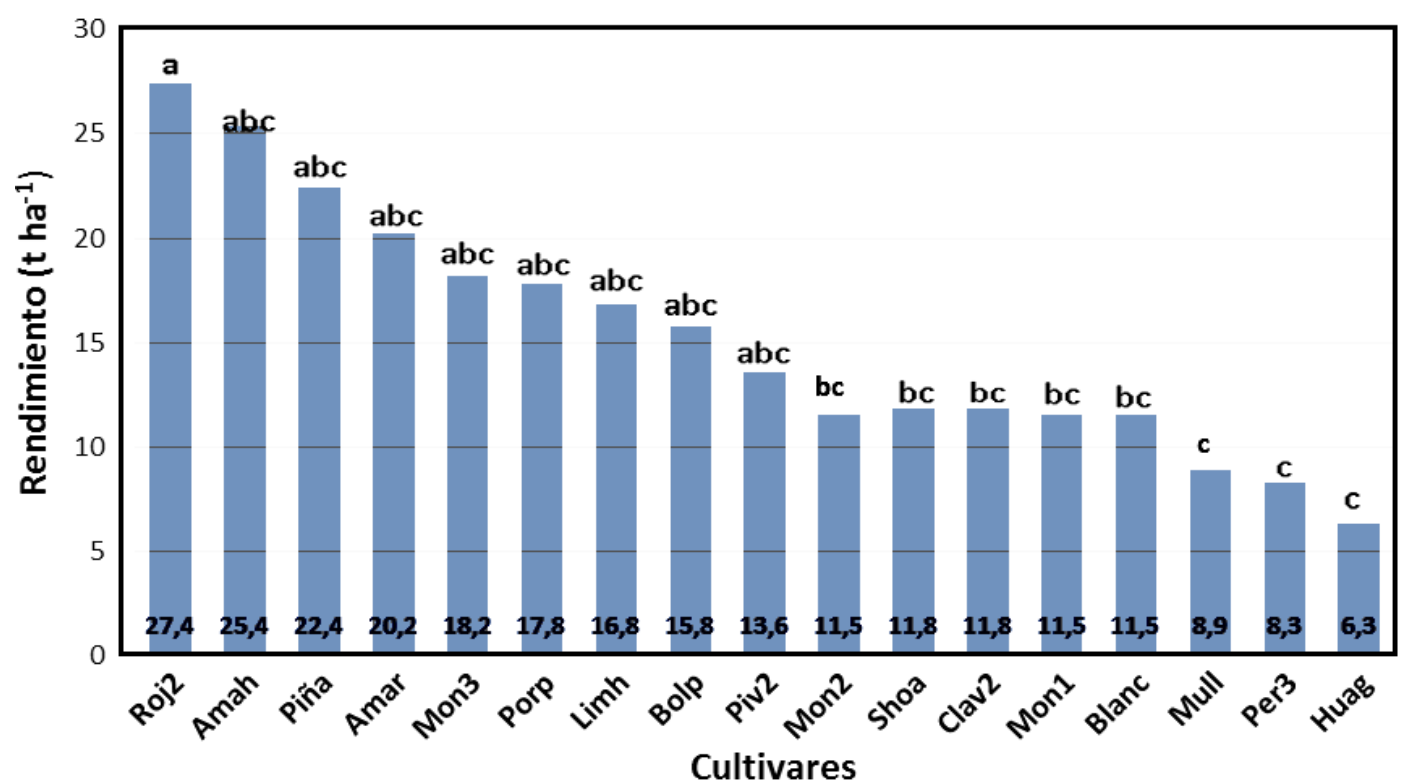

Figura 1. Rendimiento de 17 cultivares de papa chaucha (S. tuberosum grupo Phureja).

Peso total de tubérculos (PTT) y peso de tubérculos comerciales (PTC). Se encontró alta significación estadística entre tratamientos (Tabla 4) para el PTT. Es decir, los tratamientos se comportaron de modo diferente, respecto de esta variable. Asimismo, la prueba de Tukey (Tabla 6) indicó que el PTT de los cultivares Mulla, Peruanita 3 y Huagalina, es inferior al de los 14 cultivares restantes. Estos últimos conforman un grupo estadísticamente semejante, respecto a esta característica, con ventaja importante para Roja 2. El promedio (555 g.planta $\left.{ }^{-1}\right)$ y el rango de variación (296 g·planta ${ }^{-1}$ a $987 \mathrm{~g} \cdot$ planta $^{-1}$ ) del PTT (Tabla 5), fueron superiores a los informados por Rojas y Seminario (2014), quienes encontraron un PTT de 213 a 475 $\mathrm{g}$ planta $^{-1}$. Asimismo, el ANOVA para PTC (Tabla 4), indicó alta significación estadística entre tratamientos; y la prueba de Tukey correspondiente (Tabla 6), mostró que todos los cultivares son estadísticamente semejantes, excepto Huagalina, que resultó inferior al resto. Se determinó también que, la proporción de PTC, respecto al PTT, varió de 49\% (Piña amarilla) a 97\% (Mulla), con promedio de $81 \%$. Igualmente, esta proporción fue superior a la informada (49 a 66\%) por Rojas y Seminario (2014).
En comparación con los resultados de una investigación previa realizada por Rojas y Seminario (2014), dos de los ocho cultivares probados (Peruanita y Mulla), tuvieron menor rendimiento (3\% y $17 \%$ menos, respectivamente). El resto mostró rendimientos superiores $(47 \%$ más en Montañera 2 y $155 \%$ más en Amarilla), a los reportados por estos autores.

El peso promedio, por unidad, de tubérculo comercial fue de $52,1 \pm 15,5 \mathrm{~g}$ y varió de 30,0 g (Blanca) a 86,4 g (Bola de potro). Estos pesos corresponden a los tubérculos de "clase primera", de acuerdo a la clasificación de esta papa en Colombia (Perez et al., 2008, Rozo y Ñustez, 2011).

En los cultivares en estudio predominaron los tubérculos con tendencia a la forma redonda, con relación largo/ancho cercana a 1. Los cultivares con tubérculos de esta forma son los más comerciales en las ciudades del Perú.

Contenido de materia seca (MS) del tubérculo y del follaje. El rango de materia seca del tubérculo para los 17 cultivares fue de $18 \%$ a $25 \%$, con promedio de $22 \%$ (Tabla 5). Estos valores son cercanos a los reportados en la mayoría de estudios previos: Rojas y Seminario (2014), en 10 cultivares de la región Cajamarca, encontraron de $24 \%$ a $28 \%$ de MS en los 
tubérculos, con promedio de 23,5\%. En cultivares del mismo grupo, Ligarreto y Suarez (2003) encontraron entre 16\% y $27,5 \%$ de MS y Dobson et al. (2004) reportan $19 \%$ a $23 \%$ de MS en los tubérculos.

El contenido de materia seca en el follaje presentó alta variación - $10 \%$ y $29 \%-$ (Tabla 5). Este comportamiento podría explicarse, por las diferencias genéticas de los cultivares y, además, porque algunos cultivares fueron más precoces y en el momento de la evaluación tenían el follaje seco. Contrariamente, en los más tardíos, el follaje estaba parcialmente seco, al momento de la cosecha. Por lo tanto, es necesario uniformizar la evaluación de esta variable para una mejor explicación de las diferencias.

Gravedad específica (GE). La GE de los cultivares en estudio varió de 1,01 a 1,06 (Tabla 5). Estos valores están comprendidos dentro de los rangos reportados en la literatura. Ligarreto y Suarez (2003), en 50 clones, encontraron valores de 1,05 hasta 1,10, con promedio de 1,08. Pérez et al.
(2008), en el clon Criolla Colombia encontró valores de 1,09 a 1,1 y, Rodríguez et al. (2009) en nueve clones colombianos registraron 1,07 en promedio. Es necesario continuar evaluando esta variable porque tiene relación con el contenido de azúcares reductores y con la calidad de la papa para el procesamiento. Los valores recomendados para este propósito estarían alrededor de 1,08 (Rivera et al., 2011; Rozo y Nustez, 2011).

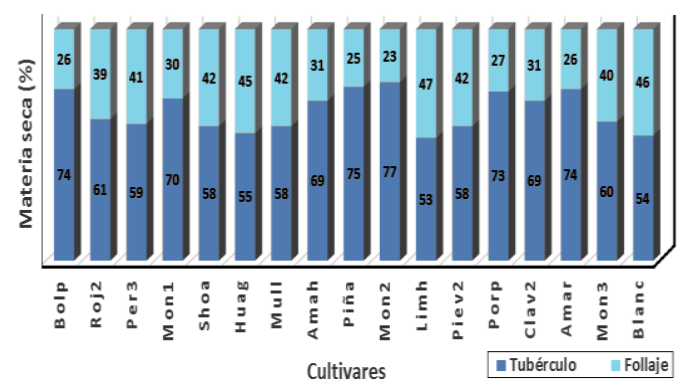

Figura 2. Asignación de materia seca a los tubérculos (= IC) y al follaje, a la cosecha, de 17 cultivares de papa chaucha (S. tuberosum grupo Phureja).

\section{Tabla 5}

Componentes del rendimiento por planta de 17 cultivares de papa chaucha (S. tuberosum grupo Phureja)

\begin{tabular}{|c|c|c|c|c|c|c|c|c|c|c|c|c|}
\hline Cultivar & $\begin{array}{l}\text { AP } \\
(\mathrm{cm})\end{array}$ & NT & NTT & NTC & $\begin{array}{c}\text { PTT } \\
\text { (g) }\end{array}$ & $\begin{array}{c}\text { PTC } \\
(\mathrm{g})\end{array}$ & $\begin{array}{l}\mathrm{LT} \\
(\mathrm{cm})\end{array}$ & $\begin{array}{l}\text { AT } \\
(\mathrm{cm})\end{array}$ & $\begin{array}{c}\text { MST } \\
(\%)\end{array}$ & $\begin{array}{l}\text { MSF } \\
(\%)\end{array}$ & GE & $\begin{array}{l}\text { IC } \\
(\%)\end{array}$ \\
\hline \multirow{2}{*}{ Bolp } & 80,4 & 2,7 & 9,3 & 5,7 & 567,7 & 492,7 & 5,7 & 4,9 & \multirow{2}{*}{25} & \multirow{2}{*}{13,3} & \multirow{2}{*}{1,06} & \multirow{2}{*}{74} \\
\hline & 0,0 & 0,4 & 1,0 & 1,0 & 68,3 & 91,5 & 1,2 & 0,9 & & & & \\
\hline \multirow{2}{*}{ Roj2 } & 91,0 & 4,1 & 27,7 & 15,3 & 987,3 & 858,0 & 5,5 & 4,6 & \multirow{2}{*}{20} & \multirow{2}{*}{14,4} & \multirow{2}{*}{1,02} & \multirow{2}{*}{61} \\
\hline & 13,0 & 0,5 & 5,3 & 2,9 & 207,0 & 168,7 & 1,3 & 0,8 & & & & \\
\hline \multirow{2}{*}{ Per3 } & 80,7 & 2,1 & 14,3 & 6,0 & 299,0 & 244,3 & 6,2 & 3,1 & \multirow{2}{*}{21} & \multirow{2}{*}{12,2} & \multirow{2}{*}{1,02} & \multirow{2}{*}{59} \\
\hline & 14,0 & 0,6 & 4,7 & 2,4 & 148,0 & 137,6 & 1,3 & 0,5 & & & & \\
\hline \multirow{2}{*}{ Mon1 } & 60,4 & 1,4 & 9,3 & 5,7 & 414,3 & 382,0 & 5,3 & 4,8 & \multirow{2}{*}{23} & \multirow{2}{*}{9,7} & \multirow{2}{*}{1,01} & \multirow{2}{*}{70} \\
\hline & 10,0 & 0,3 & 0,3 & 0,9 & 105,0 & 95,5 & 1,6 & 1,0 & & & & \\
\hline \multirow{2}{*}{ Shoa } & 86,7 & 3,4 & 22,7 & 10,0 & 424,7 & 383,3 & 4,9 & 4,4 & \multirow{2}{*}{21} & \multirow{2}{*}{14,4} & \multirow{2}{*}{1,02} & \multirow{2}{*}{58} \\
\hline & 4,0 & 1,0 & 2,8 & 1,4 & 182,0 & 185,8 & 1,3 & 0,9 & & & & \\
\hline \multirow{2}{*}{ Huag } & 67,1 & 2,7 & 15,3 & 6,0 & 227,0 & 296,3 & 5,9 & 2,9 & \multirow{2}{*}{18} & \multirow{2}{*}{12,5} & \multirow{2}{*}{1,06} & \multirow{2}{*}{55} \\
\hline & 7,0 & 1,5 & 18,0 & 2,9 & 209,0 & 241,3 & 1,9 & 0,4 & & & & \\
\hline \multirow{2}{*}{ Mull } & 74,0 & 2,1 & 15,4 & 6,0 & 322,0 & 330,0 & 6,5 & 3,2 & \multirow{2}{*}{19} & 118 & 102 & 58 \\
\hline & 4,0 & 0,3 & 5,9 & 4.0 & 257,0 & 278,6 & 1,6 & 0,6 & & & & \\
\hline Amah & 94,0 & 3,7 & 29,6 & 13,7 & 914,0 & 764,0 & 4,5 & 4,4 & 23 & & & \\
\hline Aman & 10,0 & 0,4 & 7,5 & 3,2 & 366,0 & 300,4 & 1,2 & 0,9 & 23 & 16,0 & 1,03 & 69 \\
\hline Piñ & 71,6 & 3,3 & 30,7 & 12,0 & 806,0 & 627,3 & 4,2 & 4,2 & 25 & 108 & 102 & 75 \\
\hline Fina & 32,0 & 0,7 & 4,6 & 5,2 & 354,0 & 403,8 & 1,0 & 0,7 & 25 & 10,0 & 1,02 & 13 \\
\hline Mon2 & 62,5 & 2,3 & 10,0 & 6,3 & 431,3 & 410,0 & 5,3 & 4,7 & 23 & 120 & 102 & 77 \\
\hline Mionz & 4,0 & 0,3 & 4,0 & 0,6 & 116,0 & 112,7 & 1,2 & 0,9 & 23 & 12,0 & 1,02 & 11 \\
\hline
\end{tabular}




\begin{tabular}{|c|c|c|c|c|c|c|c|c|c|c|c|c|}
\hline \multirow{2}{*}{ Limh } & 77,0 & 2,9 & 22,3 & 9,0 & 607,3 & 517,7 & 4,7 & 4,6 & \multirow{2}{*}{23} & \multirow{2}{*}{29,0} & \multirow{2}{*}{1,01} & \multirow{2}{*}{53} \\
\hline & 9,0 & 0,6 & 1,6 & 0,9 & 76,9 & 78,0 & 1,2 & 1,0 & & & & \\
\hline \multirow{2}{*}{ Piv2 } & 73,1 & 3,4 & 34,7 & 10,0 & 491,0 & 345,0 & 5,8 & 3,3 & \multirow{2}{*}{20} & \multirow{2}{*}{28,7} & \multirow{2}{*}{1,01} & \multirow[t]{2}{*}{58} \\
\hline & 6,0 & 0,3 & 7,5 & 1,9 & 86,0 & 14,3 & 1,2 & 0,5 & & & & \\
\hline \multirow{2}{*}{ Porp } & 75,7 & 3,3 & 35,0 & 12,0 & 639,3 & 473,3 & 5,1 & 3,9 & \multirow{2}{*}{24} & \multirow{2}{*}{11,9} & \multirow{2}{*}{1,02} & \multirow{2}{*}{73} \\
\hline & 18,0 & 0,4 & 8,0 & 1,2 & 160,0 & 93,5 & 0,9 & 0,6 & & & & \\
\hline \multirow{2}{*}{ Clav2 } & 56,5 & 3,0 & 29,0 & 8,7 & 422,0 & 260,3 & 5,7 & 2,8 & \multirow{2}{*}{22} & \multirow{2}{*}{14,9} & \multirow{2}{*}{1,02} & \multirow{2}{*}{69} \\
\hline & 8,0 & 0,6 & 6,7 & 3,5 & 126,0 & 111,7 & 0,9 & 0,5 & & & & \\
\hline \multirow{2}{*}{ Amar } & 80,7 & 2,6 & 26,4 & 11,3 & 726,7 & 573,3 & 4,6 & 4,3 & \multirow{2}{*}{24} & \multirow{2}{*}{11,6} & \multirow{2}{*}{1,02} & \multirow{2}{*}{74} \\
\hline & 9,0 & 0,2 & 13,0 & 2,2 & 110,0 & 153,3 & 1,2 & 0,8 & & & & \\
\hline \multirow{2}{*}{ Mon3 } & 82,6 & 2,6 & 17,2 & 7,6 & 655,7 & 573,0 & 5,7 & 4,8 & \multirow{2}{*}{23} & \multirow{2}{*}{12,6} & \multirow{2}{*}{1,05} & \multirow{2}{*}{60} \\
\hline & 8,0 & 0,6 & 9,3 & 0,9 & 124,0 & 111,8 & 1,3 & 0,9 & & & & \\
\hline \multirow{2}{*}{ Blanc } & 75,8 & 2,8 & 27,0 & 10,6 & 413,7 & 344,3 & 3,5 & 3,8 & \multirow{2}{*}{22} & \multirow{2}{*}{16,7} & \multirow{2}{*}{1,02} & \multirow{2}{*}{54} \\
\hline & 10,0 & 0,3 & 13,0 & 6,6 & 223,0 & 245,8 & 0,5 & 0,4 & & & & \\
\hline Prom. & 75,9 & 2,8 & 22,1 & 9,2 & 554,0 & 458,7 & 5,2 & 4,0 & 22,1 & 14,9 & 1,03 & 64,5 \\
\hline DS & 20,3 & 0,7 & 8,8 & 3,0 & 210,5 & 178,5 & 0,8 & 0,7 & 2,0 & 5,6 & 0,02 & 8,3 \\
\hline
\end{tabular}

Muestra: Cada dato es el promedio de 24 observaciones, excepto para MST, MSF, GE e IC (dos observaciones). El número debajo de cada dato es la desviación estándar (DS).

Significado de las abreviaturas: Bolp: Bola de potro; Mon2: Montañera 2; Roj2: Roja 2; Limh: Limeña huachuma; Per3: Peruanita 3; Piv2: Pierna de viuda 2; Mon1: Montañera 1; Porp: Porpora; Shoa: Shoga amarilla; Clav2: Clavelina 2; Huag: Huagalina; Amar: Amarilla; Mull: Mulla; Mon3: Montañera 3; Amah: Amarilla mahuay; blanc: Blanca; Piña: Piña amarilla; LT: Largo del tubérculo; AP: Altura planta; AT: Ancho mayor del tubérculo; NT: Número tallos; MST: Materia seca tubérculo; NTT: Número total tubérculos; MSF: Materia seca follaje; NTC: Número tubérculos comerciales; IC: Índice de cosecha; PTT: Peso total tubérculos; Rdto: Rendimiento; PTC: Peso tubérculos comerciales.

Índice de cosecha (IC). Entre 53\% (Limeña huachuma) y 77\% (Montañera 2) de la materia seca producida por la planta, se asignó a los tubérculos (Figura 2), el resto correspondió al follaje (tallos, hojas, flores y frutos). La proporción asignada a los tubérculos equivale al IC, que en promedio fue de $64,5 \pm 9,9 \%$. El valor del IC es un indicador de la capacidad productiva de los cultivares en estudio y es especialmente importante en cultivares con más de $70 \%$ de IC (Piña amarilla, Amarilla, Bola de potro, Montañera 2, Montañera 1, Porpora, Clavelina 2).

\section{Tabla 6}

Prueba de rango múltiple de Tukey para seis componentes del rendimiento de 17 cultivares de papa chaucha (S. tuberosum grupo Phureja)

\begin{tabular}{|c|c|c|c|c|c|c|c|}
\hline $\mathrm{N}^{\circ}$ & Cultivar & $\mathrm{AP}$ & NT & NTT & NTC & PTT & PTC \\
\hline 1 & Bolp & $94,0 \mathrm{a}$ & $1,6 \mathrm{ab}$ & $3,0 \mathrm{~b}$ & $2,3 \mathrm{~b}$ & $567,3 \mathrm{abc}$ & $492,7 \mathrm{abc}$ \\
\hline 2 & Roj2 & $91,0 \mathrm{ab}$ & $2,0 \mathrm{a}$ & $5,2 \mathrm{ab}$ & $3,9 \mathrm{a}$ & $987,3 \mathrm{a}$ & 858,0 a \\
\hline 3 & Per3 & $87,0 \mathrm{abc}$ & $1,5 \mathrm{ab}$ & $3,8 \mathrm{ab}$ & $2,4 \mathrm{~b}$ & $299,0 \quad \mathrm{c}$ & 244,3 bc \\
\hline 4 & Mon1 & $82,7 \mathrm{abc}$ & $1,1 \mathrm{~b}$ & $3,0 \quad \mathrm{~b}$ & $2,3 \mathrm{~b}$ & $414,3 \mathrm{bc}$ & $382,0 \mathrm{abc}$ \\
\hline 5 & Shoa & $81,0 \mathrm{abc}$ & $1,9 \mathrm{a}$ & $3,5 \mathrm{ab}$ & $2,5 \mathrm{ab}$ & $424,7 \mathrm{bc}$ & $383,3 \mathrm{abc}$ \\
\hline 6 & Huag & $80,7 \mathrm{abc}$ & $1,4 \mathrm{ab}$ & $4,5 \mathrm{ab}$ & $2,4 \mathrm{~b}$ & $296,3 \quad \mathrm{c}$ & $227,0 \quad \mathrm{c}$ \\
\hline 7 & Mull & $80,3 \mathrm{abc}$ & $1,4 \mathrm{ab}$ & $3,9 \mathrm{ab}$ & $2,3 \mathrm{~b}$ & $330,0 \quad \mathrm{c}$ & $322,0 \mathrm{bc}$ \\
\hline 8 & Amah & $77,0 \mathrm{abc}$ & $1,9 \mathrm{a}$ & $5,4 \mathrm{ab}$ & $3,7 \mathrm{ab}$ & $914,0 \mathrm{ab}$ & $764,0 \mathrm{ab}$ \\
\hline 9 & Piña & $76,0 \mathrm{abc}$ & $1,8 \mathrm{ab}$ & $5,6 \mathrm{ab}$ & $3,4 \mathrm{ab}$ & $806,0 \mathrm{abc}$ & $627,3 \mathrm{abc}$ \\
\hline 10 & Mon2 & $75,7 \mathrm{abc}$ & $1,5 \mathrm{ab}$ & $3,1 \quad b$ & $2,4 \mathrm{~b}$ & $431,3 \mathrm{bc}$ & $410,0 \mathrm{abc}$ \\
\hline 11 & Limh & $74,3 \mathrm{abc}$ & $1,7 \mathrm{ab}$ & $4,7 \mathrm{ab}$ & $3,0 \mathrm{ab}$ & $607,3 a b c$ & $517,7 \mathrm{abc}$ \\
\hline 12 & Piv2 & $73,0 \mathrm{abc}$ & $1,8 \mathrm{ab}$ & $5,9 \mathrm{a}$ & $3,2 \mathrm{ab}$ & $491,0 \mathrm{abc}$ & $345,0 \mathrm{abc}$ \\
\hline 13 & Porp & $71,7 \mathrm{abc}$ & $1,8 \mathrm{ab}$ & $5,9 \mathrm{a}$ & $3,5 \mathrm{ab}$ & $639,3 a b c$ & $473,3 a b c$ \\
\hline 14 & Clav2 & $67,0 \mathrm{abc}$ & $1,6 \mathrm{ab}$ & $5,4 \mathrm{ab}$ & $2,9 \mathrm{ab}$ & $422,0 \quad b c$ & $260,3 \mathrm{bc}$ \\
\hline 15 & Amar & $62,3 \mathrm{bc}$ & $1,6 \mathrm{ab}$ & $5,0 \mathrm{ab}$ & $3,4 \mathrm{ab}$ & $726,7 \mathrm{abc}$ & $573,3 \mathrm{abc}$ \\
\hline 16 & Mon3 & $60,0 \quad \mathrm{c}$ & $1,5 \mathrm{ab}$ & $4,0 \mathrm{ab}$ & $2,7 \mathrm{ab}$ & $655,7 \mathrm{abc}$ & $573,0 \mathrm{abc}$ \\
\hline 17 & Blanc & $56,7 \quad \mathrm{~d}$ & $1,6 \mathrm{ab}$ & $5,0 \mathrm{ab}$ & $3,1 \mathrm{ab}$ & $413,3 \mathrm{bc}$ & $344,3 a b c$ \\
\hline
\end{tabular}

Promedios con diferente letra en la misma columna indican diferencia mínima significativa $(\mathrm{p} \leq 0,05)$. El Significado de las abreviaturas es el mismo que en la Tabla 5. 
Estos cultivares deben ser seleccionados por su capacidad para producir cosecha. Los valores de IC encontrados en la presente investigación, fueron superiores a los informados por Rojas y Seminario (2014) - 22\% a $46 \%$-, y a la vez, son cercanos a los encontrados por Saldaña et al. (2015) en tres cultivares del grupo Phureja: $50 \%$ en los cultivares Criolla Colombia y Criolla guaneña y $83 \%$ en el cultivar Criolla latina. También son cercanos a los encontrados por Nustez et al. (2009), en cultivares mejorados de papa (71\% a $85 \%)$.

\section{Conclusiones}

Catorce cultivares de un total de 17, presentaron rendimientos superiores al promedio del grupo Phureja, reportado en la literatura. La variación general fue de 6,3 $\mathrm{t} \cdot \mathrm{ha}^{-1}$ a $27,4 \mathrm{t} \cdot \mathrm{ha}^{-1}$ y el promedio de 15,3 $\mathrm{t} \cdot \mathrm{ha}^{-1}$. Los cultivares presentaron diferencias estadísticas altamente significativas en rendimiento por hectárea, altura de planta, número de tallos, número total de tubérculos, número de tubérculos comerciales, peso total de tubérculos y peso de tubérculos comerciales. Nueve cultivares (Roja 2, Amarilla mahuay, Piña amarilla, Amarilla, Montañera 3, Porpora, Limeña huachuma, Bola de potro y Pierna de viuda 2), fueron estadísticamente superiores al resto, en rendimiento de tubérculos por hectárea. El cultivar Roja 2 fue estadísticamente superior al resto de cultivares, en rendimiento de tubérculos comerciales $\left(858 \mathrm{~g} \cdot\right.$ planta $\left.^{-1}\right)$. El cultivar Huagalina fue inferior al resto de cultivares en esta variable $\left(227 \mathrm{~g} \cdot\right.$ planta $\left.^{-1}\right)$ y un grupo de quince cultivares, estadísticamente semejantes, presentó rendimiento de tubérculos comerciales intermedio (764 a 244 $\mathrm{g} \cdot$ planta $\left.^{-1}\right)$.

Se recomienda realizar ensayos de rendimiento y calidad comercial con los mejores cultivares de la presente investigación, modificando los factores de producción como abono químico y orgánico (al suelo y foliar), época y densidad de siembra.

\section{Agradecimientos}

A la Facultad de Ciencias Agrarias de la UNC por el financiamiento de la investigación. A la Estación Meteorológica Augusto Weberbauer, Convenio UNC- SENAMHI, por el apoyo con los datos meteorológicos. A Humberto Valdez por su apoyo en el análisis estadístico.

\section{Referencias bibliográficas}

Arias, V.; Bustos, P.; Ñustez, C.E. 1996. Evaluación del rendimiento en papa criolla (Solanum phureja) variedad "Yema de huevo", bajo diferentes densidades de siembra en la Sabana de Bogotá. Agronomía Colombiana XIII (2): 152-161.

Bautista, H.F.; Ramírez, J.W.; Torres, J. 2012. Nutrient uptake of the diploid potato (Solanum phureja) variety criolla Colombia, as a reference point to determine critical nutritional levels. Agronomía Colombiana 30(3): 436-447.

Becerra-Sanabria, L.A.; Navia-de Mosquera, S.L.; ÑustezLópez, C.E. 2007. Efecto de niveles de fósforo y potasio sobre el rendimiento del cultivar 'Criolla guaneña' en el departamento de Nariño. Revista Latinoamericana de la Papa 14(1): 51-60.

Bonierbale, M.; Grüneberg, W.; Amoros, W.; Burgos, G.; Salas, E.; Porras, E.; Zum Felde, T. 2009. Total and individual carotenoid profile in Solanum phureja of cultivated potatoes: II. Development and application of near-infrared reflectance spectroscopy (NIRS) calibrations for germplasm characterization. Journal of Food Composition and Analysis 22: 509-516.

Burgos, G.; Amoros, W.; Morote, M.; Stangoulis, J.; Bonierbale, M. 2007. Iron and zinc concentration of native Andean potato cultivars from a human nutrition perspective. J. Sci. Food Agric. 87: 668-675.

Burgos, G.; Salas, E.; Amoros, W.; Auqui, M.; Muñoa, L.; Kimura, M.; Bonierbale, M. 2009. Total and individual carotenoid profiles in Solanum phureja of cultivated potatoes: I. Concentrations and relationships as determined by spectrophotometry and HPLC. Journal of Food Composition and Analysis 22: 503-508.

Cadena, M.; Naranjo, A.; Ñustez, C.E. 2005. Evaluación de la respuesta de 60 genotipos de Solanum phureja (Juz. et Buk.) al ataque de la polilla guatemalteca (Tecia solanivora Ovolny). Agronomía Colombiana 23(1): 112-116.

CIP (Centro Internacional de la Papa). 2010. Procedimientos para pruebas de evaluación de clones avanzados de papa. Guía para colaboradores internacionales. pp. 25.

Cruz, D.; Sierra, G.; Prieto, L.; Cerón, M.S. 2016. Purés deshidratados de clones candidatos a registro de papa criolla (Solanum tuberosum grupo Phureja). Compendio de resúmenes de XXVII Congreso de la Asociación Latinoamericana de la Papa. 22-26 agosto, Panamá. Instituto de Investigación Agropecuaria de Panamá. Pp. 114-115.

De Hann, S.; Thiele, G. 2005. In situ conservation and potato seed systems in the Andes. In D.I. Jarvis; R. Sevilla-Panizo; J.L. Chávez-Servia and Hodglin, T. (eds.). Seed systems and crop genetic diversity on farm. IPGRI, Rome Italy. Pp. 126-132.

De Hann, S. 2009. Potato diversity at height: Multiple dimentions of farmer-driven in situ conservation in the Andes. Ph.D. thesis Wageningen University, The Netherlands. 245 pp. 
Díaz, E.M.; Martínez, E.; Mendez, L.Y. 2008. Guías para practices de laboratorio de poscosecha en vegetales. Universidad Pedagógica y Tecnológica de Colombia. pp. 44-47.

Dobson, G.; Grffiths, D.W.; Davies, H.V.; McNicol, J.W. 2004. Comparison of fatty acid and polar lipid contents of tubers from two potato species, Solanum tuberosum and Solanum phureja. J. Agric,Food Chem. 52: 63066314.

Escallón, R.; Ramírez, M.; Ñustez, C.E. 2005. Evaluación del potencial de rendimiento y de la resistencia a Phytophthora infestans (Mon. de Bary) en la colección de papas redondas amarillas de la especie Solanum phureja (Juz. Et Buk.). Agronomía Colombiana 23(1): $35-41$.

Gardner, F.P.; Pearce, R.B.; Mitchel, R.L. 1985. Physiology of crop plants. Iowa State University Press. pp. 66.

Gabriel, J.; Plata, G.; Cadima, X.; Franco, J. 2013. Solanum phureja Juz. et Buk.: valuable source of genetic resistance to potato late blight [Phytophthora infestans (mont.) de Bary]. Revista Latinoamericana de la Papa 17(2): 131-142.

Guzman, M.; Rodríguez, P. 2010. Susceptibility of Solanum phureja (Juz. et Buk.) to potato yellow vein virus. Agronomía Colombiana 28(2): 219-224.

Hay, R.K.M.; Walker, A.J. 1989. An introduction to the physiology of crop yield. Longman Scientific \& Technical. pp. 190.

Hernández, N.C.; Suarez, J.A. 2009. Caracterización de accesiones de Solanum phureja procedentes del banco de germoplasma vegetal que administra CORPOICA por sus caracteres morfológicos, agronómicos e industriales. Trabajo de grado para optar al título de ingenieros de alimentos, Bogotá, CO. Programa de Ingeniería de Alimentos, Facultad de Ingeniería, Universidad de la Salle. $145 \mathrm{pp}$.

Huamán, Z; Spooner, D.M. 2002. Reclassification of landrace population of cultivated potatoes (Solanum Sect. Petota). American Journal of Botany 89(6): $947-$ 965.

Huamán, Z. 2008. Descriptores morfológicos de la papa (Solanum tuberosum L.). Centro de Conservación de la Biodiversidad Agrícola de Tenerife, ESP. Anexo. p. 34-35.

Leyton-Forero, G.; Abdo, R.; Prieto, L.; Poveda-Pisco, J.C. 2013. Carotenoids extracted from promising clones of criolla potato (Solanum tuberosum Phureja group) for food industry. Revista Latinoamericana de la Papa 17(2): 112-116.

Ligarreto, G.A.; Suarez, M.N. 2003. Evaluación del potencial de los recursos genéticos de papa criolla (Solanum phureja) por calidad industrial. Agronomía Colombiana 21(1-2): 83-94.

Martínez, P.; Málaga, A.; Betalleluz, I.; Ibars, A.; Velezmoro, C. 2015. Caracterización funcional de almidones nativos obtenidos de papas (Solanum phureja) nativas peruanas. Scientia Agropecuaria 6(4): 291-301.

Molina, Y.; Rabe, G.; Rodríguez, M.L.; Ceron, M.S.; Garnica, M. 2015. Conetnido de antioxidantes en papas criollas nativas (Solanum tuberosum L. grupo Phureja) en proceso de precocción y congelación. Alimentos Hoy 23 (36):31-41.

Moslemkhani, K.; Mozafari, J.; Shams Bakhsh, M.; Mohamadi Goltapeh, E. 2012. Expressions of some defense genes against Ralstonia solanacearum in susceptible and resistant potato genotypes under in vitro conditions. Iran. J. Plant. Path, 48(2): 57-60.
Ñustez, C.E.; Castellanos, M.S.; Segura, M. 2009. Acumulación y distribución de materia seca de cuatro variedades de papa (Solanum tuberosum L.) en Zipaquira, Cundinamarca (Colombia). Rev. Fac. Nal. Agr. Medellín 62(1): 4823-4834.

Parra-Galindo, M.A.; Piñeros-Niño, C.; Mosquera, T. 2016. Composición y cuantificación de antocianinas en tubérculos cocidos de Solanum tuberosum grupo Phureja. Compendio de resúmenes de XXVII Congreso de la Asociación Latinoamericana de la Papa. 22-26 agosto, Panamá. Instituto de Investigación Agropecuaria de Panamá. pp. 76-77.

Patil, U.V.; Gopal, J.; Singh, B.P.; 2012. Improvement for bacterial wilt resistance in potato by conventional and biotechnological approaches. Agric. Res. 1(4): 299316

Peña, C.B. 2015. Evaluación del contenido nutricional y actividad antioxidante en Solanum tuberosum grupo Phureja. Tesis Magister en Ciencia y Tecnología de Alimentos, Facultad de Ciencias Agrarias, Universidad Nacional de Colombia. 131 pp. Disponible en http://www.bdigital.unal.edu.co/50055/

Pérez, L.C.; Rodríguez, L.E.; Gómez, M.I. 2008. Efecto del fraccionamiento de la fertilización con $\mathrm{N}, \mathrm{P}, \mathrm{K}$ y $\mathrm{Mg}$ y la aplicación de los micronutrientes B, Mn y Zn en el rendimiento y calidad de papa criolla (Solanum phureja) variedad Criolla Colombia. Agronomía Colombiana 26(3): 477-486.

Ramírez, L.A.; Zukuaga, C.M.; Gonzales, E.P.; Alejandro, A. 2013. Uso de esquejes de tallo lateral para evaluar la resistencia de genotipos de Solanum phureja a Spongospora subterranea f. sp. subterránea. Trop. Plant Path. 38(4): 303-3012.

Rivera, J.E.; Herrera, A.O.; Rodríguez, L.E. 2011. Assessment of the processing profile of six "creole potato" genotypes (Solanum tuberosum Phureja group). Agronomía Colombiana 29(1): 73-81.

Rodríguez, O.J.; Rodríguez, L.E.; Cotes, J.M. 2013. Caracterización morfo agronómica de híbridos provenientes del cruzamiento entre especies diploides de papa. Revista Facultad de Ciencias Básicas 9(1): 54-67.

Rojas, P.; Seminario, J. 2014. Productividad de diez cultivares promisorios de papa chaucha (Solanum tuberosum grupo Phureja) de la región Cajamarca. Scientia Agropecuaria 5(4): 165-175.

Rozo, C.Y.; Ñustez, C.E. 2011. Effects of phosphorus and potassium levels on the yield of the tuber variety Criolla Colombia in the department of Cundinamarca. Agronomía Colombiana 29(2): 205-212.

Rozo, D.; Ramírez, L. 2011. La agroindustria de la papa criolla en Colombia. Situación actual y retos para su desarrollo. Gest. Soc. 4(2): 17-30.

Saldaña, T.M.; Patiño, J.A.; Cotes-Torres, J.M. 2015. Biomass distribution and allocation in diploid potato varieties (Solanum phureja Juz. Et. Buk.). Agronomía Colombiana 33(3): 322-329.

Santos, M. 2005. Evaluación del crecimiento, desarrollo y componentes de rendimiento de cuatro cultivares de papa criolla en dos localidades del departamento de Cundinamarca. Tesis MSc. Facultad de Agronomía, Universidad Nacional de Colombia. $115 \mathrm{pp}$.

Seminario, J.; Medina, W. 2009. Diversidad de papas nativas en agroecosistemas tradicionales: Caso distrito de Chota, Cajamarca, Perú. Fiat Lux 5(1): 5-24.

Seminario, J.; Zarpán, L. 2011. Conservación in situ on farm de Solanum tuberosum L. grupo Phureja en la cuenca del Llaucano y áreas adyacentes. Arnaldoa 18(2): 103-114. 
Vega, D.A. 2015. Evaluación de producción de papa criolla Solanum phureja clon paisa en contenedores de polietileno de alta densidad bajo el marco de agricultura urbana. Luna Azul 49: 35-46.

Zárate-Polanco, L.M.; Ramírez-Suarez L.M.; OtarolaSantamaría, N.A.; Prieto, L.; Garnica-Holguín, A.M; Cerón-Lasso, M.S.; Arguelles, J.H. 2014. Extracción y caracterización de almidón nativo de clones promisorios de papa criolla (Solanum tuberosum grupo
Phureja). Revista Latinoamericana de la Papa 18(1): 123.

Zimmerer, K.S. 1991. Labor shortages and crop diversity in the southern Peruvian Serra. Geographical Review 81(4): 414-432.

Zimmerer, K.S. 1992. The loss and maintenance of native crops in mountain agriculture. GeoJournal 27(1):6172. 